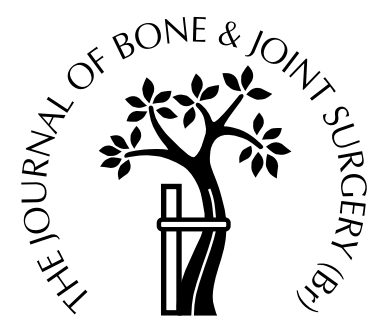

\title{
Pedicle bone grafting versus transtrochanteric rotational osteotomy for avascular necrosis of the femoral head
}

\author{
Y. Hasegawa, S. Sakano, T. Iwase, S. Iwasada, S. Torii, H. Iwata \\ From Nagoya University School of Medicine, Japan
}

\begin{abstract}
Cegmental collapse occurs in the early stage of Savascular necrosis (AVN) of the femoral head, and is associated with a poor prognosis. Since it develops at a relatively young age, the long-term outcome after total hip replacement is a major concern. We have compared the long-term results of pedicle bone grafting (PBG) with those of transtrochanteric rotational osteotomy (TRO). In the PBG group there were 23 men (27 hips) and three women ( 4 hips) with a mean age at the time of surgery of 38 years and a mean follow-up of 13 years. In the TRO group there were 44 men ( 55 hips) and 19 women (22 hips) with a mean age at the time of surgery of 39 years and a mean follow-up of seven years. Failure was defined as a need for total hip replacement or a Harris hip score below 70.

The long-term results were similar for the two groups. The survival rates at five and ten years were $85 \%$ and $67 \%$, respectively, in the PBG group, and $71 \%$ and $61 \%$, respectively, in the TRO group, according to Kaplan-Meier survivorship analysis. In the TRO group patients in stage II had significantly better results that those in stage III.
\end{abstract}

J Bone Joint Surg [Br] 2003;85-B:191-8.

Received 29 January 2002; Accepted after revision 24 July 2002

Avascular necrosis (AVN) of the femoral head is a condition of unknown aetiology which most commonly affects young people. Predisposing factors include the administration of steroids and alcohol abuse. Embolism, decompression sickness, coagulopathy, and venous congestion have also been proposed as aetiological factors. ${ }^{1-5}$

Y. Hasegawa, MD, PhD, Associate Professor

S. Sakano, MD, PhD, Consultant Orthopaedic Surgeon

T. Iwase, MD, PhD, Consultant Orthopaedic Surgeon

S. Iwasada, MD, PhD, Consultant Orthopaedic Surgeon

S. Torii, MD, PhD, Professor of Plastic and Reconstructive Surgery

H. Iwata, MD, PhD, Professor of Orthopaedics

Department of Orthopaedics, Nagoya University School of Medicine, 65

Tsurumai-cho, Showa-ku, Nagoya City 466-8550, Japan.

Correspondence should be sent to Dr Y. Hasegawa.

(C)2003 British Editorial Society of Bone and Joint Surgery

doi.10.1302/0301-620X.85B2.13190\$2.00
The natural history is favourable when the necrotic area is small. ${ }^{6-11}$ In the early stage, with little collapse, therapeutic options include core decompression, ${ }^{12-15}$ bone grafting, ${ }^{16-22}$ intertrochanteric osteotomy, ${ }^{23-26}$ and transtrochanteric rotational osteotomy. ${ }^{27-33}$ However, when the necrosis involves a large part of the weight-bearing area there is collapse of the femoral head. ${ }^{6-11}$ The resulting destructive arthritis may be treated by bipolar or total hip arthroplasty. ${ }^{34-37}$ Most patients requiring surgery are young adults aged between 20 and 50 years. The longevity of the replacement arthroplasty is a major consideration. ${ }^{35}$ Jointpreserving surgery such as core decompression, ${ }^{12-15}$ free or pedicle bone grafting, ${ }^{38-40}$ varus or valgus osteotomy, ${ }^{27-33}$ and the transtrochanteric osteotomy of Sugioka et $\mathrm{al}^{41-46}$ is available. The place of core decompression remains controversial. Curettage of the necrotic area and replacement by a pedicle bone graft are useful when the necrotic area is small. Transtrochanteric rotational osteotomy (TRO) as reported by Sugioka ${ }^{30,32}$ and Sugioka et $\mathrm{al}^{46}$ preserves the femoral head by anterior or posterior rotation when more than onethird of the joint surface is intact.

Between 1983 and 1989 we treated patients with AVN of the femoral head by pedicle bone grafting (PBG) as described by Leung and $\mathrm{Chow}^{47}$ using grafts which included the superficial or deep circumferential iliac vessels. ${ }^{19,48}$ Even with good results over more than ten years, osteoarthritis ensued. ${ }^{17}$ In 1989 we therefore began to use TRO as described by Sugioka. ${ }^{30-32,46}$

We now present and compare the results of PBG and TRO in the treatment of AVN of the femoral head.

\section{Patients and Methods}

Pedicle bone grafting. The indications for PGB were stage-II and type-I-C or type-II necrosis according to the Japanese investigation criteria for AVN of the femoral head ${ }^{7}$ (Fig. 1). The stage of necrosis was classified according to Ficat and Arlet. ${ }^{49} \mathrm{PGB}$ was performed by two surgeons (HI, $\mathrm{YH})$ using a technique described by Iwata et al. ${ }^{19}$ The graft from the iliac crest was inserted through the neck of the femur.

Twenty-six patients (31 hips) underwent PBG between 1983 and 1985 and were followed for more than ten years. There were 23 men (27 hips) and three women (4 hips) with 


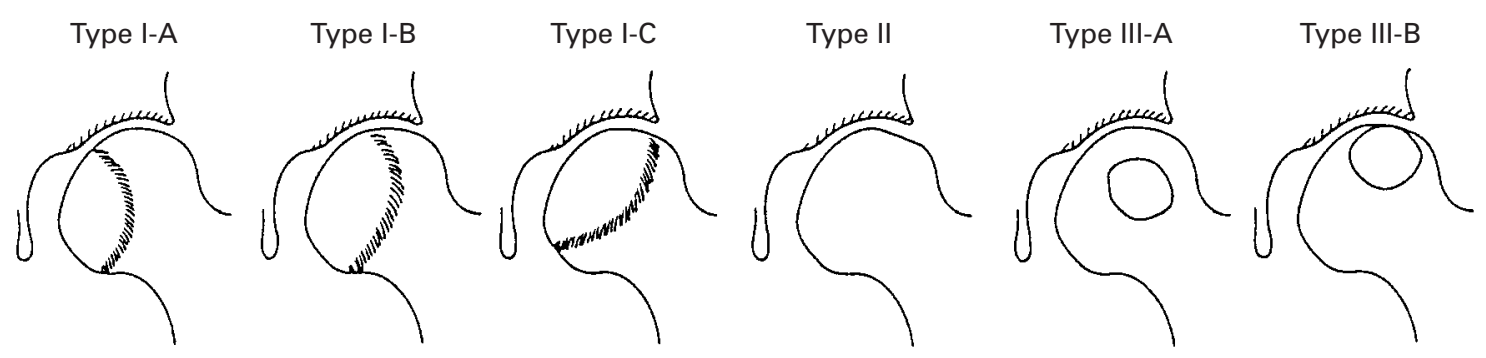

Fig. 1

Diagram showing the radiological classification of AVN of the femoral head. Type I is characterised by the presence of a demarcation line in the femoral head and divided into three subtypes, I-A, I-B and I-C, according to its relationship to the weight-bearing surface. Type II shows early flattening of the weight-bearing surface, but has no demarcation line around the necrotic area, and type III has cystic lesions and is divided into two subtypes according to their localisation in the femoral head.

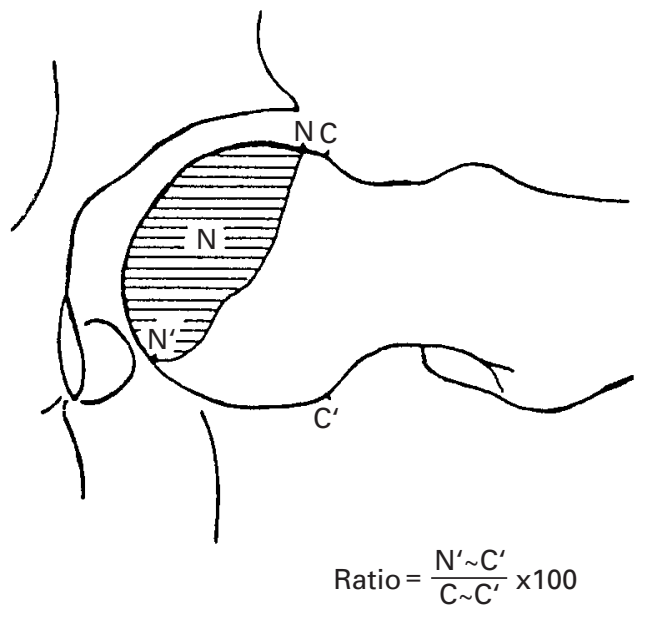

Fig. 2

Diagram showing the method of measurement of the ratio of the intact area of the posterior part of the femoral head to the total articular surface on the lateral view of a radiograph of the hip (N-N', necrotic focus; $\mathrm{C}-\mathrm{C}^{\prime}$, total joint surface).

unilateral involvement in four patients and bilateral involvement in 22. Five patients had bilateral procedures. Two were converted to total hip and bipolar arthroplasty respectively and one died seven years after surgery. Thus, 23 patients ( 28 hips) were available for final review (Table I). The vascular connection was the superficial circumflex iliac vessels except in six patients in whom the deep circumferential iliac vessels were used. The mean age at the time of surgery was 37.9 years ( 25 to 53 ), and the mean follow-up was 13 years (10 to 15). The osteonecrosis was idiopathic in five patients (7 hips), steroid-induced in six (8 hips) and alcohol-associated in 15 (16 hips). The type of AVN was type I-C in 25 hips, type II in 4, and type I-B and type III in one hip each; 28 hips were in stage II and three were in stage III.

Exercises aimed at increasing the range of movement of the hip were started in the third week after operation. At 12 weeks partial weight-bearing $(10 \mathrm{~kg})$ and at 24 weeks full weight-bearing were allowed. Crutches were used for one year.
Table I. Details of patients treated by pedicle bone grafting (PBG) and trochanteric rotational osteotomy (TRO)

\begin{tabular}{llll}
\hline & PBG & TRO & p value \\
\hline Number of hips & $31^{*}$ & 77 & \\
Mean (range) age in years & $37.9(25$ to 53$)$ & $39.0(19$ to 64$)$ & NS \\
Male : female & $23: 3$ & $44: 19$ & NS \\
Steroid-induced (\%) & $8(26)$ & $46(60)$ & 0.002 \\
Type I-C (\%) & $25(86)$ & $62(81)$ & NS \\
Stage III (\%) & $3(10)$ & $43(56)$ & 0.001 \\
Mean ( \pm SD) intact area (\%) & $53 \pm 10$ & $43 \pm 8$ & 0.02 \\
Mean (range) follow-up in years & $13(10$ to 15$)$ & $7(5$ to 11$)$ & \\
*three hips were lost to follow-up & &
\end{tabular}

*three hips were lost to follow-up

Transtrochanteric rotational osteotomy. The operation was performed by one surgeon $(\mathrm{YH})$ or supervised by him using the original technique described by Sugioka ${ }^{30}$ and Sugioka et al. ${ }^{31}$ The indications for TRO were stage III or less, type I-C and type II, with a healthy area of the femoral head which measured $36 \%$ or more in Lauenstein's view (Fig. 2). ${ }^{46}$

Between January 1989 and July 1995, 65 patients (79 hips) were operated on, of whom 63 (77 hips) were included, in this study (Table I). Two patients (two hips) with follow-up of less than five years were excluded. In ten patients who underwent conversion to total hip or bipolar arthroplasty within five years, the clinical results and radiological evaluation were recorded up to the time of conversion. There were 44 men (55 hips) and 19 women (22 hips) with unilateral involvement in 11 cases and bilateral in 55 . The mean age at the time of surgery was 39 years (19 to 64), and the mean follow-up was seven years (5 to 11). The pathogenesis was idiopathic in five patients (seven hips), steroid-induced in 40 (46 hips), and alcohol-associated in 21 (24 hips). Type I-C AVN was found in 62 hips, type II in 12 and type I-B in 3; 34 hips were in stage II of the disease and 43 were in stage III. Exercises aimed at increasing the range of movement of the hip were started in the third week after operation. At 12 weeks partial weight-bearing $(10 \mathrm{~kg})$ and at 24 weeks full weight-bearing were allowed. Crutches were used for one year.

The clinical evaluation of both groups was based on the Harris hip score and the degree of patient satisfaction, clas- 


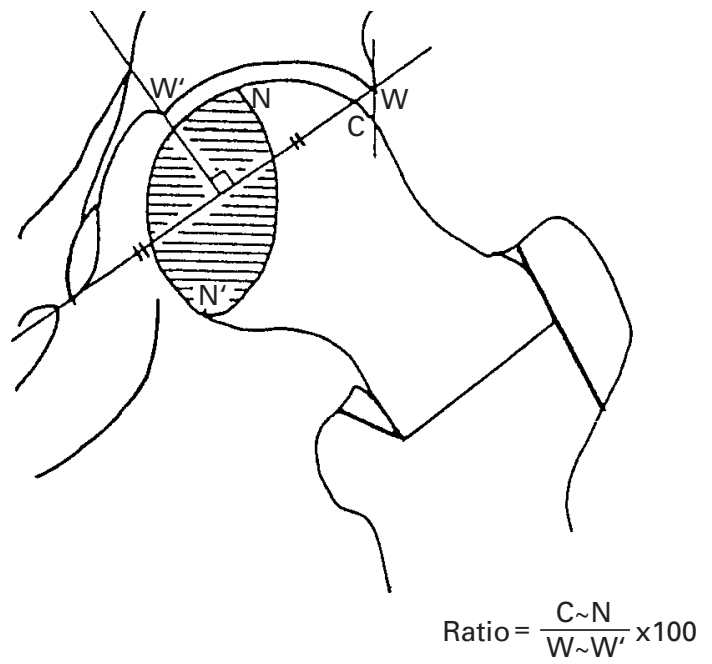

Fig. 3

Diagram showing the method of measurement of the ratio of transposed intact articular surface of the femoral head to the weight-bearing surface of the acetabulum on the postoperative AP view of the hip (N-N', necrotic focus; W-W', weight-bearing surface of acetabulum; $\mathrm{C}-\mathrm{N}$, transposed intact area by osteotomy).

sified into three grades as 'satisfied', 'dissatisfied', or 'not decided'. In the TRO group, the ratio of the transposed intact articular surface was calculated from the postoperative AP radiographs (Fig. 3). A radiological evaluation focused on the progression of the stage of AVN, was performed every year. Survivorship analysis was performed using the Kaplan-Meier method with the time of total hip or bipolar arthroplasty, the development of symptoms requiring arthroplasty or a Harris hip score of less than 70 points as the endpoint.

Statistical analysis. This was performed using Student's $t$ test, chi-squared or log-rank tests, with $\mathrm{p}<0.05$ considered to be statistically significant.

\section{Results}

Pedicle bone grafting. At the end of ten years 28 hips were intact. Conversion to total hip or bipolar arthroplasty had been required in two because of progressive collapse. In one patient collapse occurred within one year of surgery requiring a bipolar arthroplasty, and in another total hip replacement was performed nine years after surgery. One further patient died from unrelated causes. All of these patients were considered to have unsatisfactory results.

The mean Harris hip score before surgery was 69 points. It was 85 points at five years after surgery and 83 at the final review (Table II). At three years, 23 hips (74\%) were rated 'excellent' or 'good', and eight (26\%) as 'fair' or 'poor'. At five years the corresponding figures were $20(65 \%)$ and 11 (35\%), and at final review, $18(58 \%)$ and $13(42 \%)$, respectively. At the final review the Harris hip score was less than 70 points in nine hips. Conversion to total hip arthroplasty was recommended for these.
Table II. Clinical and radiological results after PBG for AVN of the femoral head $(\mathrm{n}=28)$

\begin{tabular}{lrll}
\hline & Preop & 5 years & $\begin{array}{l}\text { Final } \\
\text { review }\end{array}$ \\
\hline Mean ( \pm SD) Harris hip score & $69 \pm 9$ & $85 \pm 8$ & $83 \pm 8$ \\
Good or excellent joints (\%) & $7(13)$ & $20(65)$ & $18(58)$ \\
Stage-II hips (\%) & $28(90)$ & $13(42)$ & $11(35)$ \\
\hline
\end{tabular}

Table III. Clinical and radiological results after TRO for AVN of the femoral head $(\mathrm{n}=77)$

\begin{tabular}{llll}
\hline & Preop & 5 years & $\begin{array}{l}\text { Final } \\
\text { review }\end{array}$ \\
\hline Mean ( \pm SD) Harris hip score & $64 \pm 8$ & $84 \pm 7$ & $82 \pm 8$ \\
Good or excellent joints (\%) & $24(31)$ & $62(81)$ & $52(68)$ \\
Stage II joints (\%) & $34(44)$ & $25(32)$ & $20(26)$ \\
\hline
\end{tabular}

In the radiological evaluation before surgery, 28 hips (90\%) had been graded as stage II. At five years 13 (42\%) were stage II and at final review, 11 (35\%) (Fig. 4). At final review, 16 hips $(52 \%)$ were in stage IV; these had shown progression of the osteoarthritis at five years. The survival rates at five and ten years without failure, as calculated according to the Kaplan-Meier method, were $85 \%$ and $67 \%$, respectively (Fig. 5).

There was no difference in the results of the early and later cases, before and after the establishment of the exact surgical technique. There were no major postoperative complications, such as deep infection or fracture. Skin necrosis in the inguinal area, requiring secondary suture, occurred in three patients. Injury to the lateral femoral cutaneous nerve was noted at final review in eight patients. At final review 11 patients were satisfied, ten dissatisfied and five undecided. Return to work occurred at a mean of 175 days (76 to 380 ) after operation; 12 of the 23 men and one of the three women were still working at their original place of work.

Transtrochanteric rotational osteotomy. The mean preoperative Harris hip score was 64 points. At five years after operation it was 84 points and at final review 82 points (Table III). Early deep infection occurred in one patient, trochanteric fracture in five, pseudarthrosis in one and progressive collapse in five, requiring total hip or bipolar arthroplasty in eight. At five years after surgery, 62 hips $(81 \%)$ were rated 'excellent' or 'good', five $(6 \%)$ as 'fair' and ten $(13 \%)$ as 'poor'. At final review the corresponding figures were $52(68 \%), 8(10 \%)$, and $17(22 \%)$, respectively.

In the radiological evaluation, before operation 34 hips had been graded as stage II. At five years, 25 were stage II (32\%), and at final review, 20 (26\%) (Fig. 6). The survival rates without failure at five and ten years according to the Kaplan-Meier method were $71 \%$ and $61 \%$, respectively (Fig. 5). The difference in the survival rates at ten years in stage-II and stage-III hips was statistically significant (Fig. 7).

The overall results in the patients with a preoperatively intact area of the posterior articular surface measuring more 


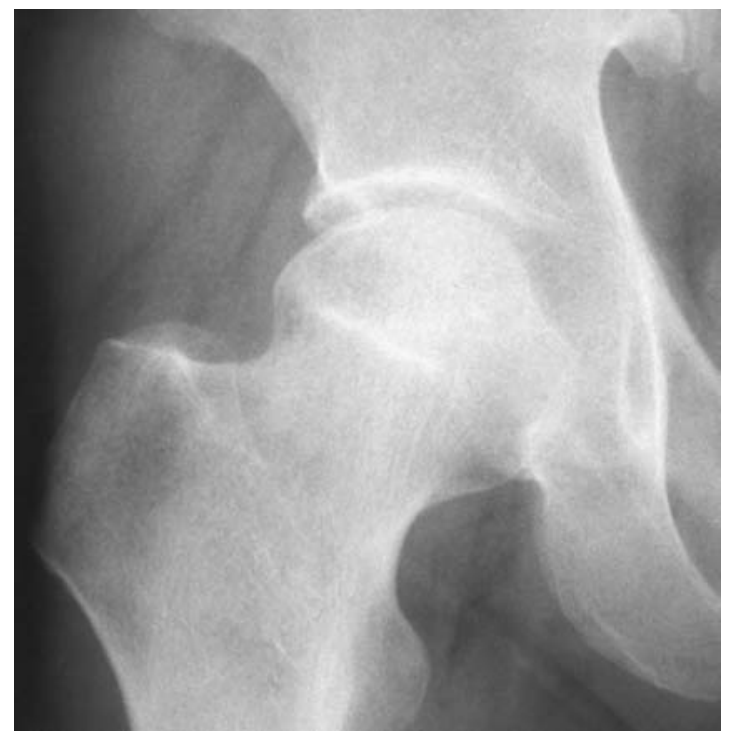

Fig. $4 \mathrm{a}$

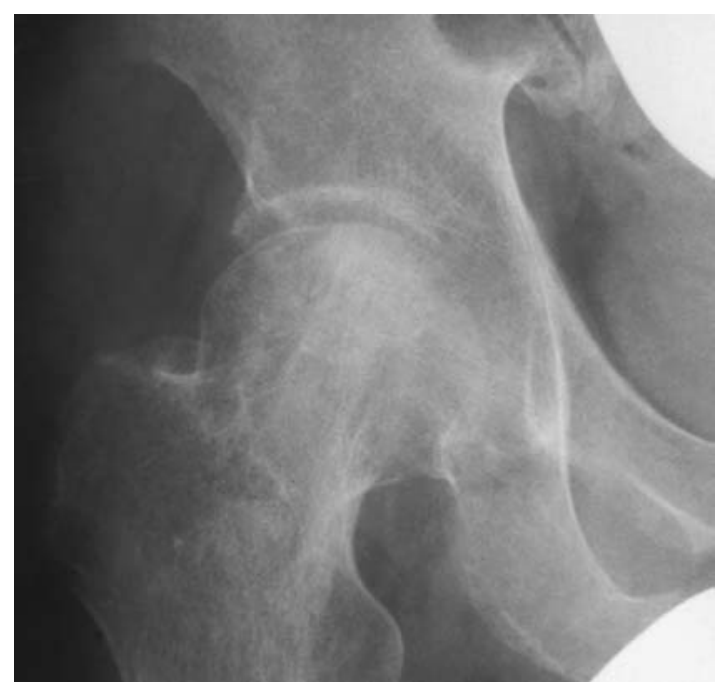

Fig. 4c

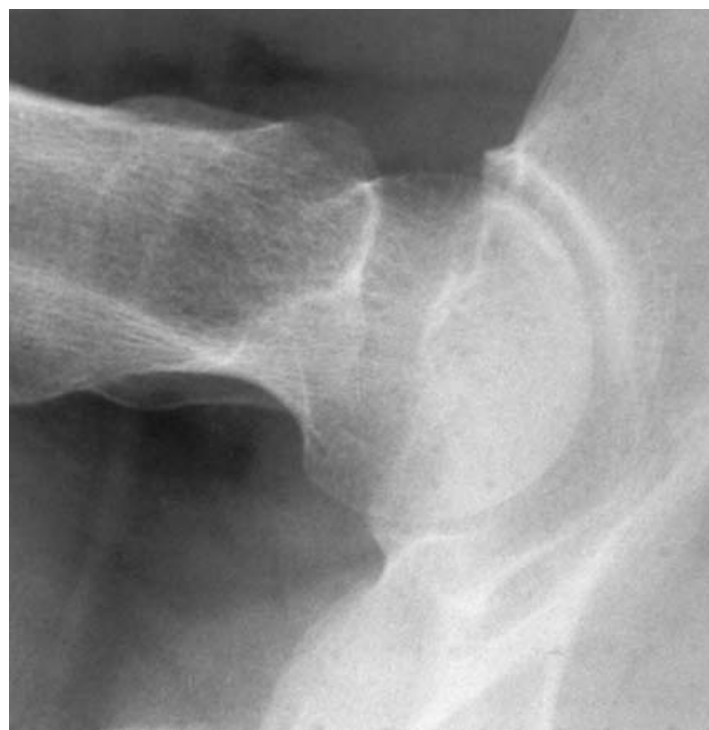

Fig. $4 b$

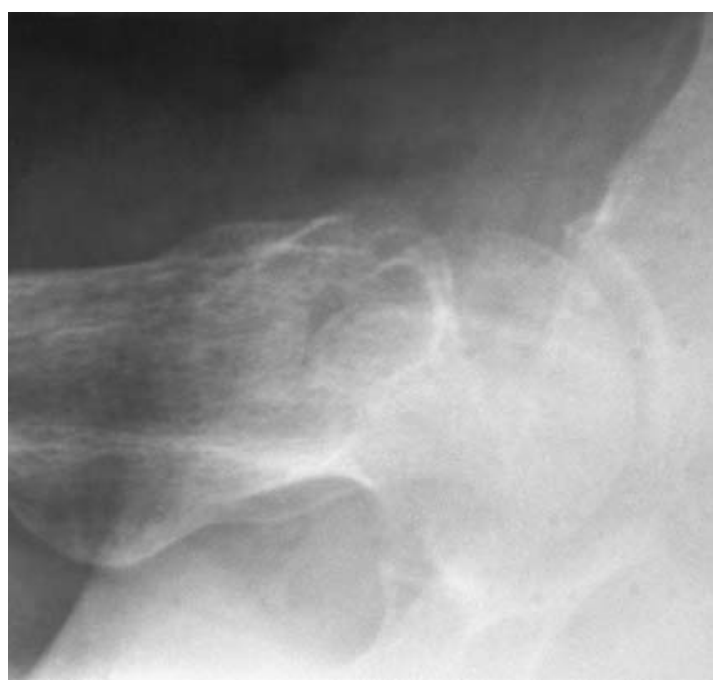

Fig. 4d

Radiographs of a 35-year-old man treated by PBG, showing preoperative a) AP and b) lateral views and postoperative c) AP and d) lateral views 12 years after PBG. The radiological classification was type I-C and stage II. The pre- and postoperative Harris hip scores were 75 and 100 points, respectively. He returned to his original occupation five months after surgery.

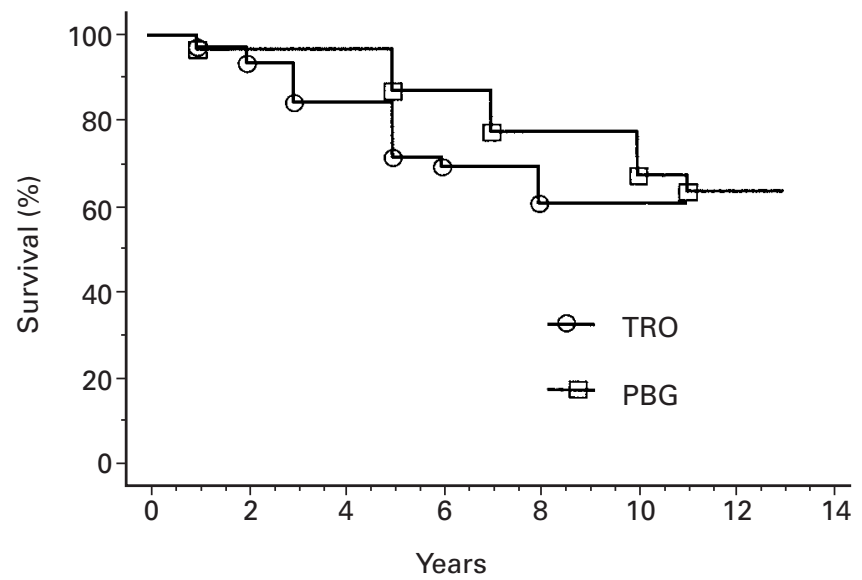

Fig. 5

Survival rates of the PBG group according to the Kaplan-Meier method. At five and ten years the survival rates in the PBG group were $85 \%$ and $67 \%$ and in the TRO group $71 \%$ and $61 \%$, respectively. The difference between the groups was not statistically significant $(\log$-rank test, $\mathrm{p}=0.16)$ 


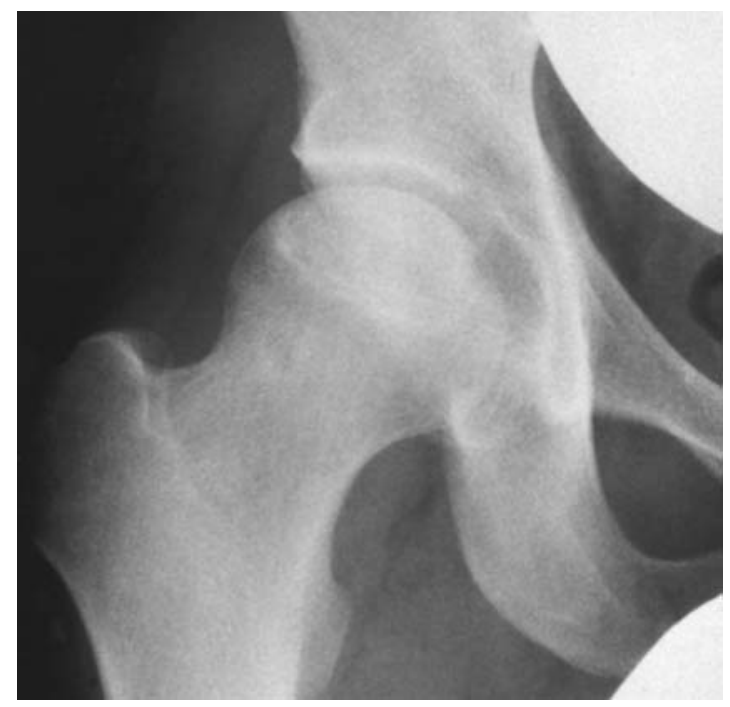

Fig. 6a

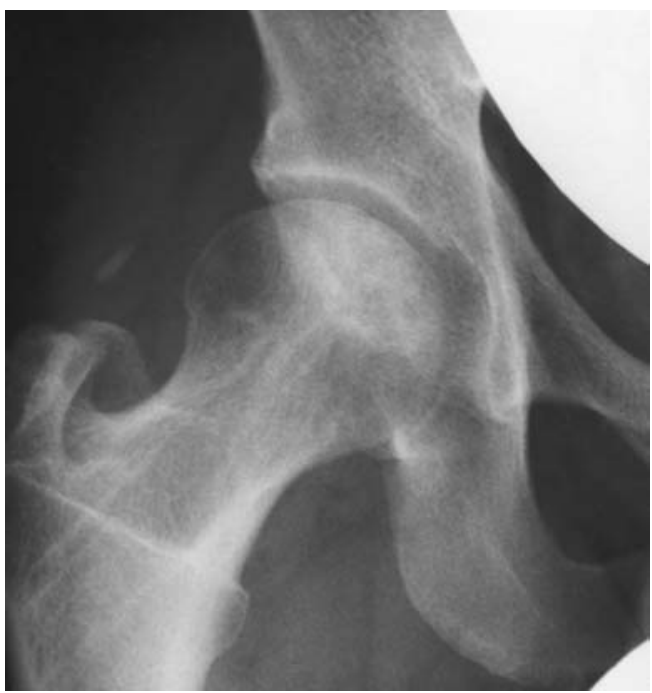

Fig. 6c

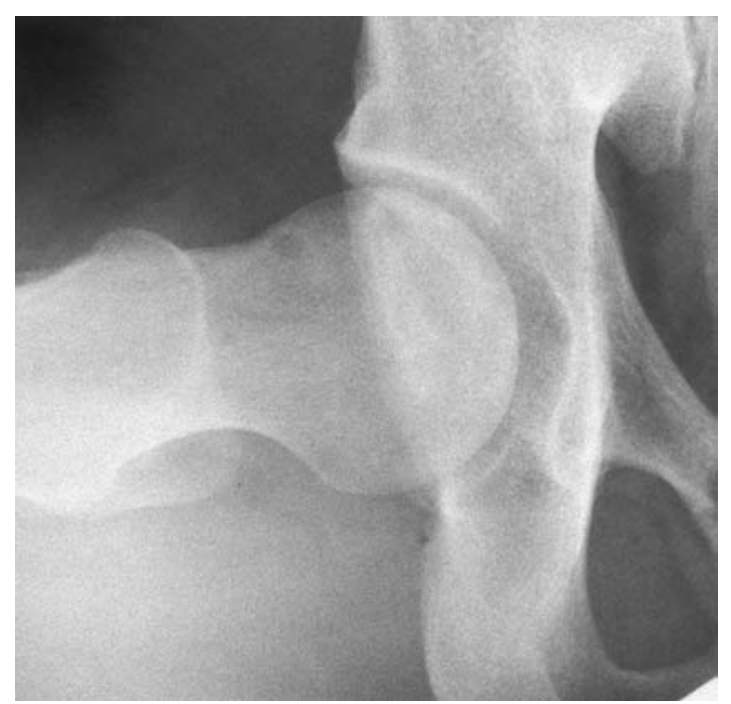

Fig. 6b

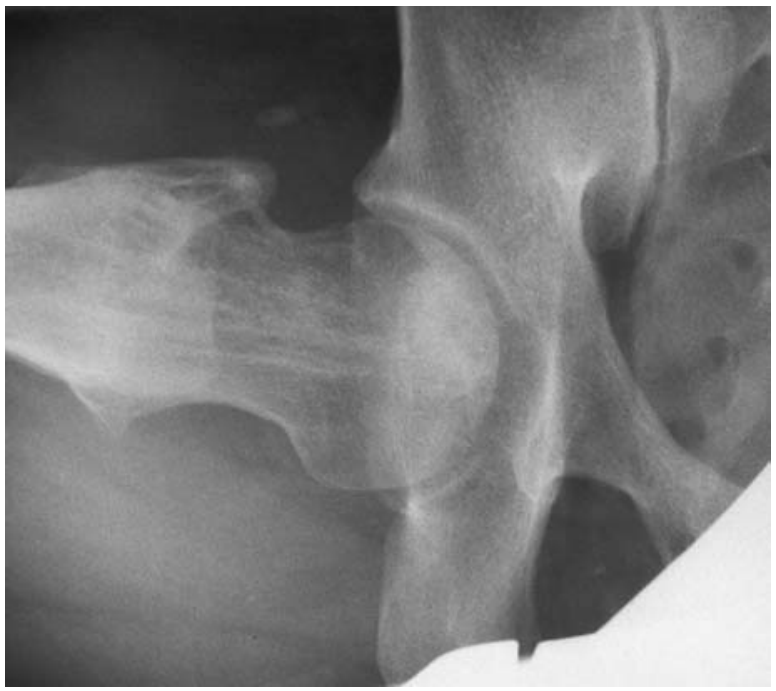

Fig. 6d

Radiographs of a 32-year-old man treated by TRO, showing preoperative a) AP and b) lateral views of the right hip and c) postoperative AP and d) lateral views seven years after TRO. The radiological classification was type I-C and stage II. Pre- and postoperative Harris hip scores were 72 and 98 points, respectively. He returned to his original occupation eight months after surgery.

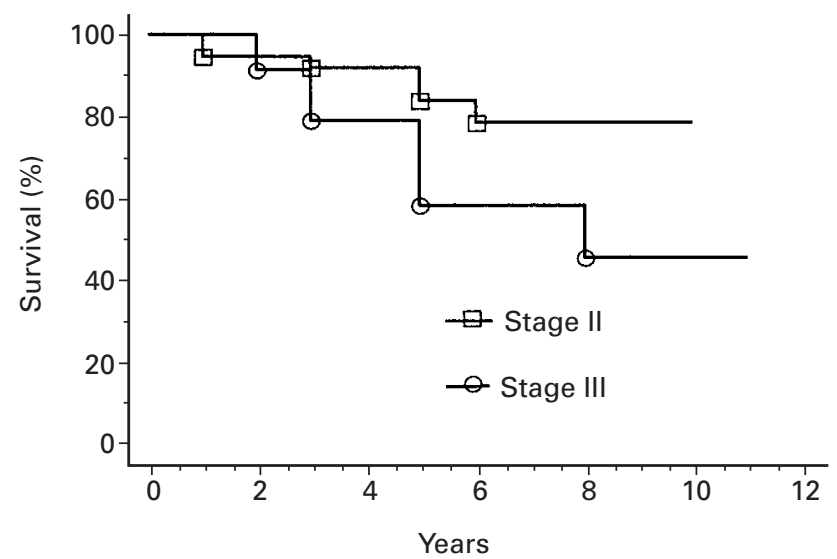

Fig. 7

Survival rates of the TRO group in stages II and III according to the Kaplan-Meier method. At ten years the rates were $79 \%$ and $45 \%$, respectively. Patients in stage II had significantly better results (log-rank test; $\mathrm{p}=$ $0.034)$. 
than $40 \%$ were significantly better than those in whom this was less than $40 \%(p=0.01)$. No difference was noted between the early and later periods, before and after the establishment of the exact surgical technique, but the results were better in patients operated on by surgeons with greater experience of TRO $(\mathrm{p}=0.04)$. At final review, 30 were satisfied, 25 dissatisfied, and eight undecided. Return to work occurred at a mean of 159 days (63 to 322); 32 men and two women were still working at their original place of work after ten years.

\section{Discussion}

The long-term prognosis of AVN of the femoral head is poor when the extent of necrosis is large $e^{6,7,9,10}$ and in such cases surgical intervention is usually required. Total hip arthroplasty has the advantages of providing relief from pain and minimising socio-economic costs with an early return to work. ${ }^{34-36}$ The results of total hip and bipolar hemiarthroplasty are good. Xenakis et $\mathrm{al}^{37}$ presented an overall survival of the prosthesis of $93 \%$ at a mean follow-up of 11.2 years. The problems of long-term durability and subsequent need for revision surgery, however, jeopardise its use in younger patients. Lachiewicz and Desman ${ }^{36}$ reported a survival rate of $52 \%$ in patients with a bipolar arthroplasty. Hartley et $\mathrm{al}^{35}$ reported a high rate of revision, $21 \%$, because of wear of polyethylene and osteolysis. ${ }^{35}$ Nevertheless, the indications for joint-preserving surgery are also controversial. When compared with total hip arthroplasty, the results of $\mathrm{PBG}$ and $\mathrm{TRO}$ are inferior with respect to relief from pain and durability. In our study, the postoperative period before returning to work was 175 and 159 days, respectively, a significant loss of employment, and approximately $50 \%$ of these patients became permanently unemployed. An investigation of the economic consequences of suspended employment in the patients should be carried out.

A weakness of our study was the difficulty of comparing the results of PBG and TRO retrospectively because of differences in the peroperative management. Both the stage of the disease and the extent of necrosis may give conflicting indications. In our study most of the patients in both groups were in stages II or III and the necrotic area was significantly larger in the TRO group than in the PBG group (Table I). A much higher percentage of the patients treated by TRO required total joint replacement. This may reflect the fact that more of the TRO patients were in stage III.

We have followed most patients in both groups for more than five years and all operations were performed or supervised by one surgeon (YH). Therefore, we were able to compare the PBG and TRO groups with regard to the clinical and radiological outcome and the degree of satisfaction. The results were similar in both groups. Similar results have also been reported using free pedicle iliac bone and fibular bone grafts (Table IV) possibly because the number of cases and length of follow-up in some series was small. Soucacos et $\mathrm{al}^{50}$ reported excellent results in 184 hips with vascular-
Table IV. Success rate after PBG for AVN of the femoral head

\begin{tabular}{|c|c|c|c|}
\hline Authors & $\begin{array}{l}\text { Number of } \\
\text { hips }\end{array}$ & $\begin{array}{l}\text { Follow-up } \\
\text { (years) }\end{array}$ & $\begin{array}{l}\text { Success } \\
\text { rate } \\
(\%)\end{array}$ \\
\hline Solonen et $\mathrm{al}^{40}$ & 13 & 4.4 & 61 \\
\hline Urbaniak et al $^{22}$ & 103 & 5.5 & $70 *$ \\
\hline 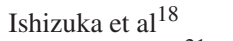 & 31 & 6.0 & 77 \\
\hline Sotereanos et $\mathrm{al}^{21}$ & 88 & 5.5 & $69 *$ \\
\hline Soucacos et $\mathrm{a}^{50}$ & 184 & 4.7 & $86 *$ \\
\hline Eisenschenk et al ${ }^{16}$ & 80 & 5.0 & 87 \\
\hline Judet and Gilbert $^{20}$ & 68 & 18.0 & $52 *$ \\
\hline Present study & 31 & 13.0 & 65 \\
\hline
\end{tabular}

*fibular graft

Table V. Success rate after TRO for AVN of the femoral head

\begin{tabular}{|c|c|c|c|}
\hline Authors & $\begin{array}{l}\text { Number of } \\
\text { hips }\end{array}$ & $\begin{array}{l}\text { Follow-up } \\
\text { (years) }\end{array}$ & $\begin{array}{l}\text { Success } \\
\text { rate } \\
(\%)\end{array}$ \\
\hline Sugioka et al ${ }^{31}$ & 128 & 2 to 9 & 77 \\
\hline Eyb and Kotz ${ }^{43}$ & 39 & 4.1 & 59 \\
\hline Tooke et $\mathrm{al}^{33}$ & 18 & 3.3 & 44 \\
\hline Matsuda et $\mathrm{al}^{29}$ & 52 & 5.1 & 69 \\
\hline Sugano et $\mathrm{al}^{45}$ & 41 & 6.3 & 56 \\
\hline Dean and Cabanela ${ }^{42}$ & 18 & 5.0 & 17 \\
\hline Langlais and Fourastier ${ }^{52}$ & 16 & 6.5 & 50 \\
\hline Atumi and Kuroki ${ }^{27}$ & 18 & 3.5 & 94 \\
\hline Noguchi et al $^{38}$ & 10 & 4.3 & $90 *$ \\
\hline Present study & 77 & 7.0 & 68 \\
\hline
\end{tabular}

*combined with pedicle bone grafting

ised fibular grafts but Judet and Gilbert ${ }^{20}$ reported good results in only $52 \%$ of 60 patients with a mean follow-up of 18 years. They concluded that the procedure may arrest or delay the progress of the condition and that it should be used in young patients without severe osteoarthritic changes in the hip.

The reported results following TRO for AVN are shown in Table V. When comparing the TRO patients in our series in stages II and III, the results of the former were better and it therefore seems important not to delay surgery. Moreover, the results of TRO were significantly better when the weight-bearing area of the femoral head was more than $40 \%$ of the total surface after surgery. If the intact area of the transposed articular surface was less than $36 \%$, the success rate was $93 \%,{ }^{46}$ but if it was less than $20 \%$, the success rate was only $29 \%$. Accordingly, surgery should be planned carefully so that an adequate weight-bearing area is obtained.

Within ten years of femoral head-preserving surgery, approximately one-third of patients show progressive collapse and osteoarthritis and require arthroplasty. A comparison of the long-term cost-effectiveness of primary and revision hip arthroplasty compared with patients with poor results of femoral head-preserving surgery which has been converted to arthroplasty, is required. The long-term results were either good or excellent in two-thirds of cases after both PBG and TRO. As noted by Dean and Cabanela, ${ }^{42}$ ethnic differences may influence the results of TRO. The 
results were significantly better in patients operated on by surgeons with more experience of TRO, emphasising the technically demanding nature of this procedure. ${ }^{28,51}$ Many complications including early failure of internal fixation, progression of varus deformity, trochanteric and cervical fracture, and further collapse of the head, have been reported after TRO. ${ }^{28,45,51}$ In our study most complications, such as varus deformity due to failure of fixation or subtrochanteric fracture, occurred early in the series. ${ }^{28}$ Many authors have developed fixation devices to minimise early failure of fixation. ${ }^{41,52}$

In order to obtain the best clinical and radiological results, considerable surgical skill and strict adherence to the indications for surgery are required. In our study, the results obtained after PBG and TRO were similar. As a therapeutic plan in a young patient, even when collapse of the femoral head has progressed (stage III), anterior or posterior TRO, is our first choice. Further follow-up is required to record the progression of osteoarthritis.

We thank Professor Hans Wingstrand and Dr Kiyoharu Kawabe for their instructions and assistance with the preparation of the manuscript. We also thank Professor Youich Sugioka for his technical advice.

No benefits in any form have been received or will be received from a commercial party related directly or indirectly to the subject of this article.

\section{References}

1. Asherton RA, Liote F, Page B, et al. Avascular necrosis of bone and antiphospholipid antibodies in systemic lupus erythematosus. $J$ Rheumatol 1993;20:284-8.

2. Glueck CJ, Freiberg R, Tracy T, Stroop D, Wang P. Thrombophilia and hypofibrinosis: pathophysiologies of osteonecrosis. Clin Orthop 1997;334:43-56.

3. Jones JP Jr. Intravascular coagulation and osteonecrosis. Clin Orthop 1992;277:41-53.

4. Nishimura T, Matsumoto T, Nishino M, Tamita K. Histopathologic study of veins in steroid treated rabbits. Clin Orthop 1997;334:37-42.

5. Wang GJ, Sweet DE, Reger SI, Thomson RC. Fat-cell changes as a mechanism of avascular necrosis of the femoral head in cortisone-treated rabbits. J Bone Joint Surg [Am] 1977;59-A:729-35.

6. Ito H, Matsuno T, Kaneda K. Progression of early stage avascular necrosis of the femoral head. Clin Orthop 1999;358:149-57.

7. Ohzono K, Saito M, Takaoka K, et al. Natural history of nontraumatic avascular necrosis of the femoral head. J Bone Joint Surg [Br] 1991;73B:68-72.

8. Shimizu K, Moriya H, Akita T, Sakamoto M, Suguro T. Prediction of collapse with magnetic resonance imaging of avascular necrosis of the femoral head. J Bone Joint Surg [Am] 1994;76-A:215-23.

9. Steinberg ME, Bands RE, Parry $\mathbf{S}$, et al. Does lesion size affect the outcome in avascular necrosis? Clin Orthop 1999;367:262-71.

10. Sugano N, Takaoka K, Ohzono K, et al. Prognostication of nontraumatic avascular necrosis of the femoral head: significance of location and size of the necrotic lesion. Clin Orthop 1994;303:155-64.

11. Takatori Y, Kokubo T, Ninomiya $\mathbf{S}$, et al. Avascular necrosis of the femoral head: natural history and magnetic resonance imaging. $J$ Bone Joint Surg [Br] 1993;75-B:217-21.

12. Fairbank AC, Bhatia D, Jinnah RH, Hungerford DS. Long-term results of core decompression for ischemic necrosis of the femoral head. J Bone Joint Surg [Br]1995;77-B:42-9.

13. Ficat RP. Idiopathic bone necrosis of the femoral head. $J$ Bone Joint Surg [Br] 1985;67-B:3-9.

14. Saito S, Ozhono K, Ono K. Joint-preserving operation for idiopathic avascular necrosis of the femoral head: results of core decompression, grafting and osteotomy. J Bone Joint Surg [Br]1988;70-B:78-84.

15. Steinberg ME, Larcom PG, Strafford B, et al. Core decompression with bone grafting for osteonecrosis of the femoral head. Clin Orthop 2001;386:71-8.
16. Eisenschenk A, Lautenbach M, Schwetlick G, Weber U. Treatment of femoral head necrosis with vascularized iliac crest transplants. Clin Orthop 2001;386:100-5.

17. Haswegawa Y, Iwata H, Torii S, et al. Vascularized pedicle bone grafting for nontraumatic avascular necrosis of the femoral head: a five to eleven year follow-up. Arch Orthop Trauma Surg 1997;116:251-8.

18. Ishizuka M, Sofue M, Dohmae $Y$, Endo N, Takahashi H. Vascularized iliac bone graft for avascular necrosis of the femoral head. Clin Orthop 1997;337:140-8.

19. Iwata H, Torii S, Hasegawa Y, et al. Indications and results of vascularized pedicle iliac bone graft in avascular necrosis of the femoral head. Clin Orthop 1993;295:281-8.

20. Judet H, Gilbert. Long-term results of free vascularized fibular grafting for femoral head necrosis. Clin Orthop 2001;386:114-9.

21. Sotereanos DG, Plakseychuk AY, Rubash HE. Free vascularized fibular grafting for treatment of osteonecrosis of the femoral head. Clin Orthop 1997;344:243-56.

22. Urbaniak JR, Coogan PG, Gunneson EB, Nunley JA. Treatment of osteonecrosis of the femoral head with free vascularized fibular grafting: a long-term follow-up study of one hundred and three hips. J Bone Joint Surg [Am] 1994;77-A:681-94.

23. Jacobs MA, Hungerford DS, Krackow KA. Intertrochanteric osteotomy for avascular necrosis of the femoral head. J Bone Joint Surg [Br] 1989;71-B:200-4.

24. Maistrelli G, Fusco U, Avai A, Bombelli. Osteonecrosis of the femoral head treated by intertrochanteric osteotomy: a four- to 15 -year followup. J Bone Joint Surg [Br] 1988;70-B:761-6.

25. Mont MA, Fairbank AC, Krackow KA, Hungerford DS. Corrective osteotomy for osteonecrosis of the femoral head: the results of a longterm follow-up study. J Bone Joint Surg [Am] 1996;78-A:1032-8.

26. Scher MA, Jakim I. Intertrochanteric osteotomy and autogenous bonegrafting for avascular necrosis of the femoral head. J Bone Joint Surg [Am] 1993;75-A:1119-33.

27. Atsumi T, Kuroki Y. Modified Sugioka's osteotomy: more than 130 degrees posterior rotation for osteonecrosis of the femoral head with large lesion. Clin Orthop 1997;334:98-107.

28. Iwasada S, Hasegawa Y, Iwase T, Kitamura S, Iwata H. Transtrochanteric rotational osteotomy for osteonecrosis of the femoral head: 43 patients followed for at least 3 years. Arch Orthop Trauma Surg 1997;116:447-53.

29. Matsuda T, Matsuno T, Hasegawa I, et al. Results of transtrochanteric rotational osteotomy for nontraumatic osteonecrosis of the femoral head. Clin Orthop 1988;228:69-74.

30. Sugioka Y. Transtrochanteric anterior rotational osteotomy of the femoral head for the treatment of osteonecrosis: a new osteotomy operation. Clin Orthop 1978;130:191-201.

31. Sugioka Y, Katsuki I, Hotokebuchi T. Transtrochanteric rotational osteotomy of the femoral head for the treatment of osteonecrosis. Clin Orthop 1982;169:115-26.

32. Sugioka Y. Transtrochanteric rotational osteotomy in the treatment of idiopathic and steroid induced femoral head osteonecrosis, Perthes disease, slipped capital femoral epiphisis and osteoarthritis of the hip: indication and results. Clin Orthop 1984;184:12-23.

33. Tooke SMT, Amstutz HC, Hedley AK. Results of transtrochanteric rotational osteotomy for femoral head osteonecrosis. Clin Orthop 1987;224:150-7

34. Cabanela ME. Bipolar versus total hip arthroplasty for avascular necrosis of the femoral head: a comparison. Clin Orthop 1990;261:5962

35. Hartley WT, McAuley JP, Culpepper WJ, Engh CA Jr, Engh CA Sr. Osteonecrosis of the femoral head treated with cementless total hip arthroplasty. J Bone Joint Surg [Am] 2000;82-A:1408-13.

36. Lachiewicz PF, Desman SM. The bipolar endoprosthesis in avascular necrosis of the femoral head. J Arthroplasty 1988;3:131-8.

37. Xenakis TA, Gelalis J, Koukoubis TA, Zaharis KC, Soucacos PN. Cementless hip arthroplasty in the treatment of patients with femoral head necrosis. Clin Orthop 2001;386:93-9.

38. Noguchi M, Kawakami T, Yamamoto $H$. Use of vascularized pedicle iliac bone graft in the treatment of avascular necrosis of the femoral head. Arch Orthop Trauma Surg 2001;121:437-42.

39. Rosenwasser MP, Garino JP, Kiernan HA, Michelsen CB. Longterm follow-up of thorough debridement and cancellous bone grafting of the femoral head for avascular necrosis. Clin Orthop 1994;306:1727 
40. Solonen KA, Rindell K, Paavilainen T. Vascularized pedicle bone graft into the femoral head: treatment of aseptic necrosis of the femoral head. Arch Orthop Trauma Surg 1990;109:160-3.

41. Atsumi T, Muraki M, Yoshihara S, Kajihara T. Posterior rotational osteotomy for the treatment of femoral head osteonecrosis. Arch Orthop Trauma Surg 1999;119:388-93.

42. Dean MT, Cabanela ME. Transtrochanteric anterior rotational osteotomy for avascular necrosis of the femoral head: long-term results. Bone Joint Surg [Br] 1993;75-B:597-601.

43. Eyb R, Kotz R. The transtrochanteric anterior rotational osteotomy of Sugioka: early and late results in idiopathic aseptic femoral head necrosis. Arch Orthop Trauma Surg 1987;106:161-7.

44. Koo KH, Song HR, Yang JW, et al. Transtrochanteric rotational osteotomy for osteonecrosis of the femoral head. J Bone Joint Surg [Br] 2001;83-B:83-9.

45. Sugano N, Takaoka K, Ohzono K, et al. Rotational osteotomy for non traumatic avascular necrosis of the femoral head. J Bone Joint Surg [Br] 1992;74-B:734-9.
46. Sugioka Y, Hotokebuchi T, Tsutui H. Transtrochanteric rotationa osteotomy for idiopathic and steroid-induced necrosis of the femoral head. Clin Orthop 1992;272:111-20.

47. Leung PC, Chow YYN. Reconstruction of proximal defects with a vascular-pedicled graft. J Bone Joint Surg [Br] 1984;66-B:32-7.

48. Hasegawa Y, Matsuda T, Iwasada S, et al. Scintigraphic evaluation of transtrochanteric rotational osteotomy for osteonecrosis of the femoral head: comparison between scintigraphy, radiography and outcome in 34 patients. Arch Orthop Trauma Surg 1998;117:23-6.

49. Ficat RP, Arlet J. Ischemia and necrosis of bone. Baltimore, Williams and Wilkins, 1980.

50. Soucacos PN, Beris AE, Malzos K, et al. Treatment of avascular necrosis of the femoral head with vascularized fibular transplant. Clin Orthop 2001;386:120-30.

51. Braunstein EM, Weissman BN, Sosman JL, Drew M. Complications of intertrochanteric rotational osteotomy. Skeletal Radiol 1983;10:258-61.

52. Langlais F, Fourastier J. Rotation osteotomies for osteonecrosis of the femoral head. Clin Orthop 1997;343:110-23. 